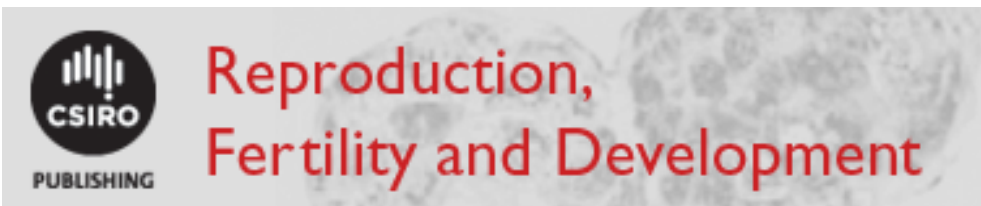

\title{
Seventy years of progestagen treatments for management of the sheep estrous cycle: where we are and where we should go
}

\begin{tabular}{|r|l|}
\hline Journal: & Reproduction, Fertility and Development \\
\hline Manuscript ID & Draft \\
\hline Manuscript Type: & Review \\
\hline Author: & n/a \\
\hline Complete List of Authors: & $\begin{array}{l}\text { Gonzalez-Bulnes, Antonio; Dpto. Reproduccion Animal. INIA } \\
\text { Menchaca, Alejo; Fundación IRAUy, Instituto de Reproducción Animal } \\
\text { Uruguay } \\
\text { Martin, Graeme; University of Western Australia, Faculty of Agriculture } \\
\text { and Natural Sciences } \\
\text { Martinez-Ros, Paula; Universidad Cardenal Herrera-CEU, CEU } \\
\text { Universities }\end{array}$ \\
\hline Keyword: & $\begin{array}{l}\text { artificial insemination, assisted reproductive technology, progesterone, } \\
\text { prostaglandin }\end{array}$ \\
\hline
\end{tabular}

\section{SCHOLARONE \\ Manuscripts}




\section{Seventy years of progestagen treatments for management of the sheep}

\section{2 estrous cycle: where we are and where we should go}

3

\section{Antonio Gonzalez-Bulnes ${ }^{A, B, G}$, Alejo Menchaca $^{\text {C,D }}$, Graeme B. Martin ${ }^{\text {, }}$, Paula \\ $5 \quad$ Martinez-Ros ${ }^{\mathrm{F}}$}

6

7 A Dpto. de Reproduccion Animal, SGIT-INIA, Avda, Puerta de Hierro, s/n, 28040, Madrid, $8 \quad$ Spain

9 B Dpto. de Toxicologia y Farmacologia, Facultad de Veterinaria, UCM, Ciudad Universitaria, $10 \mathrm{~s} / \mathrm{n}, 28040$, Madrid, Spain

11 C Instituto de Reproducción Animal Uruguay, Fundación IRAUy, Camino Cruz del Sur 2350, 12 Montevideo, Uruguay

13 D Programa de Posgrado, Facultad de Veterinaria, Universidad de la República, Av. Lasplaces, $14 \quad 1550$, Montevideo, Uruguay

15 E UWA Institute of Agriculture, The University of Western Australia, 35 Stirling Highway, 16 Crawley, WA 6009, Australia

17 F Dpto. Produccion y Sanidad Animal, Facultad de Veterinaria, Universidad Cardenal Herrera18 CEU, CEU Universities, C/ Tirant lo Blanc, 7. 46115 Alfara del Patriarca Valencia, Spain 


\section{Abstract}

23

24 The management of the ovine estrous cycle is mainly based on the use of exogenous

25 hormones for mimicking (progesterone and its analogues) or manipulating (prostaglandin

$26 \quad \mathrm{~F}_{2 \alpha}$ and its analogues) the activity of the corpus luteum, combined with the application of

27 other hormones mimicking the pituitary secretion of gonadotrophins (e.g.: equine 28 chorionic gonadotrophin, eCG). These protocols have been applied without major change

29 for decades but, now, there are two reasons to reconsider them: i) our greatly improved

30 knowledge of the dynamics of ovarian physiology, following the application of transrectal

31 ultrasonography, indicates that modification of the protocols may improve the yields; ii)

32 increasing concerns about animal health and welfare, food safety and the environmental

33 impact of the treatments, as evidenced by public opinion and therefore market forces.

34 Here, we offer an overview of these issues, introduce an updated protocol, and suggest

35 ways for future improvements of the protocols.

$37 \quad$ Additional keywords

38 Artificial-insemination, breeding, eCG, progesterone, prostaglandins. 
40

41

42

\section{The first 70 years}

0

The control of estrus and ovulation in sheep, as in other species, has probably been a goal in animal husbandry for thousands of years (Martin 1995), been the focus of intense research for at least 80 years because of the practical goals of achieving synchronized lambing, higher fecundity and fertility, inducing out-of-season breeding, and advancing puberty. In addition to the immediate productivity gains, these outcomes facilitated genetic improvement when associated with artificial insemination, superovulation and embryo transfer.

The research journey towards control of estrus and ovulation probably started with the work of Dutt and Casida (1948) who published the first data showing that daily progesterone injections, over 14 successive days, could be used to control the ovine cycle.

During the treatment, estrus and ovulation were blocked and then, when the injections stopped, fertile mating ensued within 2 days. Four years later, a single dose of pregnant mare serum gonadotrophin (PMSG; currently known as equine chorionic gonadotrophin, eCG) injected at the cessation of progesterone treatment proved to be effective for inducing estrus and ovulation during seasonal anestrus (Dutt 1952, Robinson 1952). Since then, eCG has also become an essential component of protocols for fixed-time artificial insemination (FTAI) because it ensures a narrow interval between ovulation and insemination.

Two other findings of note were achieved during the 1950s and 1960s (Robinson and Lamond 1966); a) the development of two potent progestagen analogues (Shelton 1965),

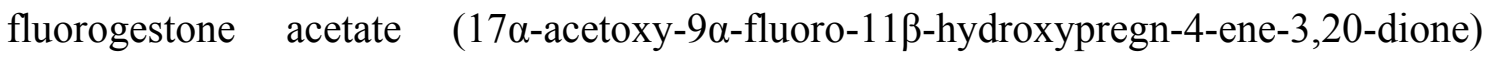


developed by G.D. Searle \& Company (today a subsidiary of Pfizer), and

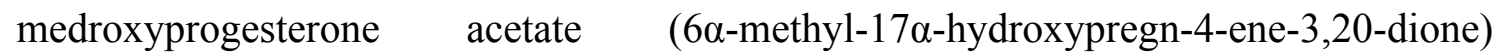
developed in 1956 by Syntex and the Upjohn Company; b) the development of vaginal pessaries ('sponges') impregnated with these progestogens that, over a long period of time, liberated the analogues and allowed them to be taken up by the vaginal mucosa (Robinson 1964, 1965), thus minimizing animal handling. During the 1970s and 1980s, there were major advances in the field of controlled drug delivery systems, such as the silicone intravaginal devices containing progesterone that could be applied to ruminant reproduction (reviewed by Rathbone et al. 1997). For sheep reproduction, these CIDRtype devices (Figure 1) were developed by AHI Plastic Moulding Company in conjunction with the Ministry of Agriculture \& Fisheries of New Zealand (Wheaton et al. 1993), and offered advantages in terms of treatment efficacy and animal health (Hamra et al. 1986, 1989, Wheaton et al. 1993, dos Santos-Neto et al. 2015) that we will consider later in this manuscript.

Since that time, almost all protocols for induction and synchronization of estrus and ovulation in sheep have been based on the insertion of progestagen-impregnated intravaginal devices for 12-14 days, followed by the intramuscular injection of eCG at device removal (Abecia et al. 2012). The practical convenience of these protocols was considered to out-weigh the somewhat lower fertility that follows application of progestagens compared to natural estrus, apparently caused by alterations in the patterns of LH secretion (Gordon 1975, Scaramuzzi et al. 1988), in the quality of the corpora lutea (Killian et al. 1985) and in sperm transport and survival in the female reproductive tract (Hawk and Conley 1971). The use of intravaginal sponges for periods as long as 12-14 days was also related to the presence of abnormal (purulent or hemorrhagic) and fetid 
vaginal discharges at their removal that, in turn, were associated with lower pregnancy rates (Scudamore 1988). These features led to the development of modifications in the protocols, devices and periods of treatment (Figure 2) that we will consider below.

In our current changing world, the strengthening influence of public opinion, accelerated by social media and leading to new market forces, is challenging synchronization protocols with concerns about animal health and welfare, food safety, and environmental impact, as is happening for many other intervention strategies in livestock management (Martin et al. 2004).

\section{Implications of intravaginal devices for animal health and welfare}

The main concern related to animal health and welfare when using progestagenimpregnated polyurethane sponges is caused by the induction of vaginitis, with purulent or hemorrhagic fetid vaginal discharges at sponge removal and, in the worst case, adhesion of the device to the vaginal mucosa. The cause is inflammation and infection associated with proliferation and changes in the vaginal microbiota (Sargison et al. 2007; Martins et al. 2009; Vasconcelos et al. 2016). The initial event is a physical effect due to the constant retention of vaginal secretion when intravaginal sponges are left in situ for long periods of time (Al-Hamedawi et al. 2003). Changes in vaginal secretion and $\mathrm{pH}$ encourage the proliferation of natural inhabitants of the vagina, such as Salmonella spp. and Staphylococcus aureus (Swartz et al. 2014), as well as Escherichia coli of fecal origin (Vasconcelos et al. 2016). A particularly important causal agent of purulent vaginitis in ewes is S. aureus (Bragança et al. 2017). 
114 In addition to the negative effects on fertility, described early on by Scudamore (1988), the induction of vaginitis is contrary to the principles of animal health and welfare. One solution is adequate prophylactic management, including the cleaning and disinfection of the vulva and surrounding area, as well as all the materials used for device application, in combination with the application of local or systemic antibiotics concurrently with sponge insertion (Gatti et al. 2011; Vasconcelos et al. 2016). However, this approach is obviously contrary to contemporary drives to limit the use of antimicrobials.

Despite the depressive effects of progestagens on vaginal immunity (Lewis 2003), the effects of intravaginal sponges are mainly caused by their physical presence, because hormone-free sponges also cause vaginitis (Al-Hamedawi et al. 2003; Suarez et al. 2006). Consequently, the use of alternatives to the sponge should make the use of antibiotics unnecessary. The Controlled Internal Drug Releasing device (CIDR) was developed in the late 1980s (Knight and Hall 1988; Wheaton et al. 1993). It is a T-shaped, solid silicone-based device loaded with progesterone, in contrast to the porous polyurethane sponges impregnated with progestagens. The ovine CIDR has been widely used in the Americas, Australia, New Zealand, the Middle East and Africa ever since it was developed, but it was not authorized for commercial use in the European Union until 2018 (Martinez-Ros et al. 2018a). The DICO device, developed more recently (Vilariño et al. 2010), is also based on a silicone matrix containing progesterone and is commercially available for use in sheep and goats in some countries in the Americas, Oceania, the Middle East and Africa. With these silicone devices, the incidence of vaginitis and adhesion is greatly reduced, compared to sponges (Suarez et al. 2006) because the design and structure allows a better drainage of vaginal secretions. In fact, only around $15 \%$ of the sheep treated with CIDR show vaginal discharges, and those discharges are always 
scarce, clear and mucous, without significant changes in the vaginal microbiota

140 (Martinez-Ros et al., unpublished). Hence, there is no need for the application of antibiotics. Therefore, as has happened in cattle, it is clear that silicone intravaginal devices will replace sponges in sheep. In addition to the advantages related to animal health and welfare, the CIDR-type devices offer better reproductive outcomes.

\section{Efficiency (fertility yields) of intravaginal hormonal treatments}

As previously mentioned, there were early reports that fertility after progestogen treatment is lower than at natural estrus, with evidence of deficiencies in sperm transport and survival at the female reproductive tract (Hawk and Conley 1971), alterations in the patterns of LH release (Gordon 1975, Scaramuzzi et al. 1988) and the quality of the postovulatory corpora lutea (Killian et al. 1985). More recent studies have added to this list of explanations by assessing the ovulatory follicles in the ovaries after administration of a progesterone analogue (i.e., fluorogestone acetate). There are deficiencies in the secretion of estradiol during the preovulatory phase, in the production of an oocyte that can be fertilized and develop into a viable embryo, and in the secretion of progesterone by the subsequent corpora lutea (Gonzalez-Bulnes et al. 2005; Berlinguer et al. 2007).

The deficiencies in the ovulatory follicles seem to be related to the length of the progestogen treatment (Menchaca and Rubianes 2004; Gonzalez-Bulnes et al. 2005). Exogenous progestagen is thought to inhibit tonic LH secretion (negative feedback) and therefore prevent the occurrence of estrus and positive feedback (and thus the LH surge and ovulation) until it is withdrawn (Goodman and Karsh 1980). The low levels of tonic 
developing in the ovaries. These follicles need LH for their maintenance and development and, when LH concentrations are low, they can undergo atresia, allowing the emergence and growth of new ovulatory follicles (Nöel et al. 1994, Leyva et al. 1998). However, sometimes, at the end of the period of progestagen treatment, the intravaginal devices are almost exhausted and releasing too little progestagen to fully suppress LH secretion. The consequence is abnormal follicular development leading to large persistent follicles (Johnson et al. 1996; Viñoles et al. 1999) that are old and therefore lead to poor produce fertility after ovulation (Ungerfeld and Rubianes 1999; Viñoles et al. 2001).

To avoid the period of low levels of progesterone/progestagen release, the duration of device insertion can be minimized by using protocols based on short-term treatment (Ungerfeld and Rubianes 1999, Knights et al. 2001, Viñoles et al. 2001, Menchaca and Rubianes 2004). These protocols have mainly been studied with CIDR-type intravaginal devices inserted for 5-7 days (Menchaca et al. 2018). The advantage of the CIDR is that it provides high progesterone concentrations immediately after insertion, due to the release kinetics - solid progesterone particles are dispersed homogeneously in a relatively thin coating over an inert polymer spine. This is effectively a saturated solution and the release of progesterone is controlled by diffusion from the inner to the outer layers of the coating, then into the vaginal fluid, the vaginal tissue and the blood stream (de Graaff and Grimard 2018). High blood progesterone concentrations obtained at CIDR insertion promote follicular turnover by reducing LH support, leading to the recruitment of a new follicle that reaches a preovulatory diameter 5-7 days after device insertion (Menchaca and Rubianes 2004). 
188 Such period of 5-7 days is shorter than the half-life of a possible corpus luteum so, in cycling animals, it is necessary to induce luteolysis with a single dose of prostaglandin (PG) $\mathrm{F}_{2 \alpha}$ or its analogues, at either insertion or the removal of the intravaginal device (Menchaca and Rubianes 2004, Letelier et al. 2009, Cox et al. 2012). However, with $\mathrm{PGF}_{2 \alpha}$ injection at device insertion, a percentage of ewes do not respond to the treatment because they are in the early luteal phase and their corpora lutea are not yet sensitive to prostaglandin, so $\mathrm{PGF}_{2 \alpha}$ injection at device removal is the better option (Martinez-Ros et al. 2018b).

Compared to long-term protocols, short-term protocols are as effective for inducing estrus, ovulation and fully functional corpora lutea (Martinez-Ros et al. 2018b), and the resulting fertility is never lower, but usually similar or higher (Menchaca et al. 2018). For all of these reasons, short-term protocols are now being used more frequently for artificial insemination of sheep under field conditions, although they are still far less popular among producers than the classical long-term treatments. Clearly, we need a campaign to explain and promote short-term protocols.

Another advantage of the short-term protocols is related to the induction of vaginitis and the use of antibiotics. Antibiotics are not necessary with short-term treatments, even if sponges are used - the incidence of vaginal discharges is similar to long-term treatments (around 100\%; Martinez-Ros et al. unpublished results) but there is less effect on vaginal $\mathrm{pH}$, microbiota, and the incidence of hemorrhagic or purulent discharges (around $10 \%$ in short-term protocols and around $85 \%$ in long-term protocols; Martinez-Ros et al. unpublished results). 
213 Finally, short-term protocols with CIDR-type devices permit the re-use of the devices

214 after adequate washing and disinfection, with similar outcomes to those obtained with

215 first-use devices (Vilariño et al. 2010, 2013, Pinna et al. 2012, Menchaca et al. 2018),

216 thus reducing the cost of the treatments. The high content of progesterone remaining in

217 the CIDR after the first use also opens the door to the development of new devices with

218 a lower progesterone content and the development of new polymers with improved

219 release dynamics (de Graaff and Grimard 2018).

220

221 Environmental security of intravaginal hormonal treatments

222

223 Intravaginal hormonal treatments also carry the risk of residues flowing into the

224 environment - both the device itself (sponge or CIDR) and the hormone it contains. Of

225 particular concern is the potential impact on aqueous biosystems where progestagen

226 release could affect the physiology and behavior of the indigenous animals. This situation

227 adds extra value to the possibility of reusing CIDRs to halve the number discarded, and

228 also the development of new devices with lower contents of progesterone and better

229 polymers (de Graaff and Grimard 2018). Either way, there would be less residual

230 progesterone in the device after use, and the risk of liberation into the environment would

231 be reduced. 


\section{Food security and the use of intravaginal hormonal devices}

At present, consumer perceptions about food production present an interesting duality consumers are distant from, and unfamiliar with, current animal production systems. This disconnection leads to poor knowledge that is exacerbated by the romantic images presented in advertisements, provoking a negative attitude towards the intensive animal industries that are necessary for providing the abundant, low-cost foods they desire. On the other hand, the consumers are correct in being concerned about animal health, animal welfare, and food safety. With regard to food safety, pesticides, antimicrobials and hormones are seen as main hazards. The link between the food and hormone is stigmatized in public opinion in spite of the fact that that hormones are naturally produced by both animals and humans and are, often, identical molecules that are essential for functions such as growth, performance and reproduction. In fact, improvement of these functions in livestock has been the main driver for their use in industry - reducing costs and increasing efficiency in animal production.

Growth and performance of farm animals can be improved by treatment with anabolic steroids and such steroids were therefore widely used from the 1930s until the demonstration of an increase in genital and breast cancer following the consumption of meat exposed to diethylstilbestrol (a synthetic estrogen) in the 1960s (BCERF 2000). The use of diethylstilbestrol in food production was phased out in the 1970s and nowadays the use of other hormones is strongly regulated. Only five different kinds of steroid hormones are authorized for food production in United States and Canada (progesterone, 
257

258

259

260

261

262

263

264

265

266

267

268

269

270

271

272

273

274

275

276

277

279

280

281

in Canada. Conversely, the European Union has adopted a zero-tolerance policy on the use of hormones for promoting growth (Pasantino 2012, Regal et al. 2012).

However, social opinion still persists and may prejudice the use of steroid hormones for managing reproduction (e.g.: intravaginal progestagens treatments). For example, in 1996, the Swedish Farmers Association banned the use of estrus synchronization protocols in Sweden in response to consumer attitudes. In the rest of the world, scientific evidence prevails so progestagens are authorized for therapeutic or husbandry purposes when administered by a veterinarian or under a veterinarian's supervision. Such authorization includes the synchronization of estrus, improvement of fertility and preparation of donors and recipients for embryo implantation. In these situations, hormones are used for a limited period of time and treated animals are consumed long after withdrawal of the hormone treatments, so there are no residues. In fact, plasma progesterone concentrations decrease to basal levels within 12 hours of device withdrawal (Vilariño et al. 2010).

Clearly, progesterone is naturally produced by the corpus luteum, so the meat or milk concentrations may be slightly higher in treated than untreated animals, but the levels are still within the normal range of untreated animals, so there is no risk of increased exposure (BCERF 2000). In fact, it can be shown that people already eat hormones naturally present in food (e.g.: steroids from plants; female animals in luteal phase or early pregnancy) at even higher concentrations than in products from animals treated for reproductive management (Fingleton 2004). Specifically, the progestagen treatments for control of ovulation in female animals should induce similar or even slightly lower progesterone concentrations, and at a shorter length, than those reached during the luteal 
282 phase or pregnancy, since excessively greater concentrations may negatively affect the 283 efficiency of the treatments (Carvalho et al. 2008). In any case, progestagens are 284 protective for the genital tract. Specifically, women under estradiol therapy for prevention 285 of menopause-related symptoms are also treated with progesterone and medroxyprogesterone acetate to prevent endometrial cancer (NAMS 2017). Moreover, there is evidence that progesterone supplementation is protective again breast cancer (Fournier et al. 2014). Obviously, this situation is not the case for the general population and only refers to women treated with estrogens, but it provides a relevant example of the lack of risk in the use of intravaginal progestagen treatments in breeding animals.

\section{Regulation of hormone efficacy, quality and safety}

Hormones used for reproductive management, like any other veterinary drugs, are of controlling the drugs used on animals, adopted by several international regulatory bodies, is the preservation of the animal health and the improvement of animal production without affecting the environment and public health (Fingleton 2004). In this scenario, according to FAO guidelines (Rutter 1993), drug safety is the highest priority for regulatory pharmaceutical bodies. These bodies consider drug manufacture, import, distribution and use; the regulations for use include consideration of the actual animal being treated, other animals in contact with it, the veterinarian or the technician administering the medication, the consumer of products from the treated animals, and the environment. This regulatory system is subject to permanent control and update, and assures that every drug in the market (including hormones used for reproduction) is safe enough if used as indicated under good veterinary practice. 
308 The regulations for veterinary products are executed by local Regulatory Agencies, according to the legislation of each country, and usually follow the system implemented by reference administrations such as the US or EU. In fact, the process for approval of a veterinary product involves a complex and rigorous control, and is defined in the guidelines published by the Veterinary International Conference on Harmonization (VICH). VICH is a trilateral program (US, EU, Japan) that aims to harmonize technical requirements for veterinary product registration. This program provides recommendations on the studies necessary to guarantee the safety of the target animals and the user administering to the animal, the adequacy of environmental risk assessments, the definition of maximum residue limits, and the withdrawal periods for human food (https://www.ema.europa.eu/en/veterinary-regulatory/research-development/scientificguidelines/safety-residues/safety-residues-pharmaceuticals\#environmental-riskassessment).

These regulatory rules guarantee that progesterone for intravaginal therapeutic and husbandry uses in cattle, sheep, goats and horses (Anadon et al. 2018) is safe for target animals, human health and environment. The Food and Drug Administration, in the case of US, and The European Medicament Agency, in the case of EU, assign a withdrawal period of zero days for meat and milk (milk can be used for human consumption during 327 the treatment), which demonstrates no doubt about the safety of progesterone treatments in female ruminants. Moreover, the Codex Alimentarius of the FAO considers it unnecessary to establish Maximum Residue Limits for progesterone, because residues resulting from the use of this substance in accordance with good animal husbandry 
to

pose

$a$

hazard

to

human

health

332 (www.fao.org/input/download/standards/45/MRL2_2015e.pdf).

The situation with other hormones used for reproductive management is the same as that

for progesterone. Compounds like $\mathrm{PGF}_{2 \alpha}, \mathrm{GnRH}, \mathrm{FSH}$ and $\mathrm{LH}$ are normally produced by the female and the exogenous treatments aim to induce similar circulating concentrations that evoke the same effects as the endogenously secreted hormone. Heterologous gonadotrophins like eCG and hCG deserve similar consideration because the pharmacokinetics and pharmacodynamics are similar to those of the endogenous gonadotrophins, and the molecules are recognized and bound specifically by LH or FSH receptors, so there are no additional or side effects. Thus, concerns about the use of these hormones to improve reproduction have no scientific support so, consequently, most of them are approved by international regulatory systems and available worldwide. However, consumers operate on emotion, not data, and providing data does not change them. This is the problem with the 'deficit model' in science communication, which is extremely difficult to overcome.

In addition to efficacy, quality and food safety for humans, animal health and welfare are also assessed before any progesterone intravaginal device is approved (e.g., according to VICH GL 43 Target Animal Safety; https://www.ema.europa.eu/en/vich-gl43-targetanimal-safety-pharmaceuticals). In this procedure, the females are subjected before, during and after treatment, to: a) physical observation and examination, comfort evaluation soon after intravaginal device insertion, body condition score and body weight, body temperature, heart rate and respiratory rate, and other factors; b) haematology, blood chemistry, urinalysis (hemogram, hematocrit, hemoglobin, red blood cell count, mean 
corpuscular volume, leukocytes, granulocytes, lymphocytes, monocytes, urea, creatinine, total protein levels, glutamic oxaloacetic transaminase, glutamic pyruvic transaminase, creatine phosphokinase, fibrinogen, and other factors); and c) reproductive safety studies, particularly vulva and vagina examination by vaginoscopy, uterus and ovarian evaluation by ultrasonography.

A different issue is that, sometimes, the use of chemical products in livestock has economic and trade implications. According to FAO documents, such as Legislation for Veterinary Drugs Control (Fingleton 2004), the international emphasis on veterinary drug regulation has mainly focused on trade liberalization, so barriers to trade have been under scrutiny. Controls on the movement of animals and animal products, and on products that have been treated with certain chemicals, are clearly barriers to free trade when no scientific support is argued. In accordance with World Trade Organization requirements, in particular the Agreements on Agriculture, on the Application of Sanitary and Phytosanitary Measures (the $\quad$ SPS Agreement; https://www.wto.org/english/tratop_e/sps_e/spsagr_e.htm), and on Technical Barriers to Trade (https://www.wto.org/english/tratop_e/tbt_e/tbt_e.htm), such controls are acceptable provided that they are based on international standards (as set by the World Animal Health Association and Codex Alimentarius Commission), or can be justified on scientific grounds (Fingleton 2004). In this scenario, barriers to pharmacological treatments for ovarian control without scientific support become trade barriers, which usually occur from developed to developing countries. This situation has drastic consequences, especially for farmers from countries without livestock subsidies, and where assisted reproductive technologies are invaluable for improving flock efficiency and productivity. 
An added problem: Societal opinion on the use of eCG with progestagen treatment

Currently, the most challenging issue for protocols based on progesterone/progestagen is

not the correct progestagen treatment but the concomitant use of eCG. Administration of

eCG is essential for induction of ovulations in anestrous sheep and for precise synchronization of ovulation before artificial insemination and embryo transfer. In addition, eCG is used for increasing the percentage of twin pregnancies throughout the year, even with natural mating. The use of eCG is therefore crucial for flock reproductive management, as well as the implementation of ARTs in sheep.

However, in European countries, there is a strong animal rights movement that is against the use of eCG and it has forced the production of eCG to move from The Netherlands to Iceland, and even out of Europe to South America and Asia. European activists are currently seeking the banning of eCG imports from these countries. The hormone, eCG, is secreted by the endometrial cups of pregnant mares and released into the blood stream from where it is obtained by jugular venopuncture. This is a very minor procedure but animal rights activists consider it to be cruel. Despite the pressure, the EU does not currently plan to ban the importation of eCG because the mares used for producing the hormone are kept in agreement with the animal welfare principles - specifically, according to the standards on "Use of animals in research and education" of the World Organization for Animal Health (OIE) and the current Directive EU 2010/63 on the protection of animals used for experimental and scientific purposes 
406 In spite of the opinion of the EU Government, societal pressure against companies

407

408

409

410

411

412

413

414

415

416

417

418

419

420

421

422

423

424

425

426

427

428

429

430

manufacturing eCG products may force them to discontinue use of the hormone. The consequences of the withdrawal of eCG for European sheep producers, especially those relying on artificial insemination, breeding during anestrus, or embryo transfer, are profound because there is no other product with similar activity and indications. Moreover, there would be similar consequences for other livestock species and experimental animals used in biomedicine, because eCG is also widely used for reproductive management of cattle, goats, pigs, rabbits, rats and mice.

The activism against the equine hemoderivative hormone production may affect other medical products used for animal and human health because procedure is the same as the method recommended by the World Human Organization (WHO) for equine antisera production

(http://www.who.int/bloodproducts/AntivenomGLrevWHO_TRS_1004_web_Annex_5.pdf).

The production of equine therapeutic antisera has been categorized as a high priority by the WHO, mainly in regions where snake bites, scorpion stings and exposure to rabies have a great impact on public health. In fact, envenoming and rabies affect more than 14 million people annually, especially in the developing world, according with WHO (http://apps.who.int/iris/bitstream/10665/43858/1/9789241563482_eng.pdf). There is still no effective treatment other than administration of therapeutic antisera, which are often unavailable or unaffordable, particularly in Africa and Asia. This situation results in high mortality and morbidity, mainly of children and young agricultural workers, with grave socioeconomic consequences, and therapeutic antisera, mainly produced by equine blood collection, are therefore included in the WHO Essential Medicines List (http://apps.who.int/iris/bitstream/handle/10665/273826/EML-20-eng.pdf). Clearly, any 
431 concern about hemoderivative products from horses goes beyond the use of eCG in sheep, and we predict that a ban on this production system will affect critical therapies for human health.

\section{The next 70 years}

Having witnessed how the deepening knowledge of ovarian physiology has led to the improvement and widespread application of reproductive biotechnologies in ruminants (Menchaca et al. 2018, Mapletoft el al. 2018), it is still clear that estrus synchronization for FTAI and embryo transfer in the ewe, as in other ruminants, will continue to require the use of progesterone and eCG, and that progesterone treatment associated with FSH will be needed for superovulation and embryo production programs. Novel improvements to conventional protocols have been proposed, but most of them continue to use the same hormones. That said, it is also clear that barriers that reduce the availability of any of these hormones would hinder the application of reproductive technologies with negative consequences for livestock productivity and global food production.

Viable alternative protocols have been proposed for FTAI, but there are no alternatives for the use of exogenous progesterone, before or during FSH treatment, in ovarian superstimulation for embryo production. For FTAI protocols, PGF2 $\alpha$ reappeared early in the 2000 s as a possible alternative to progesterone, mainly because progesterone intravaginal devices were not available in the US and EU (Menchaca and Rubianes 2004). However, this restriction was subsequently lifted and CIDR-type devices are now available and approved worldwide. Currently, new PGF2 $\alpha$ treatment schemes for 
456 insemination without estrous detection. The original prostaglandin-based treatments that

457 had been developed in the 1970s and 1980s consisted of two doses of PGF $2 \alpha$ 458 administrated 9-14 d apart (Fierro et al. 2013), but estrus is expressed over a wide 4-day 459 window, so heat detection is needed if the females are to be inseminated $12-24 \mathrm{~h}$ after the 460 onset of the estrus. When females were inseminated at a fixed time, lower pregnancy rates 461 resulted (Boland et al. 1978, Hackett et al. 1981, Gordon 1983, Evans and Maxwell 462 1987).

463

464 With the introduction of ultrasonography to study ovarian physiology in the 1990s, it was 465 found that the poor temporal association of estrus and ovulation following PGF2 $\alpha$ 466 treatment was due to poor control of follicular development in sheep (Viñoles and 467 Rubianes 1998; Rubianes et al. 2003) as well as cattle (Kastelic and Ginther 1991). We now know that, in sheep, follicular wave emergence occurs approximately every 5 days (Evans 2003) and the ovine corpus luteum is sensitive to PGF2 $\alpha$ as early as 3 days after ovulation (Rubianes et al. 2003) instead of 5 days as was believed (Wiltbank and Niswender 1992). These new insights finally enabled the use of PGF2 $\alpha$ to control the estrus and ovulation (Menchaca and Rubianes 2004). Various studies published in the 1990s and 2000s demonstrated that any prostaglandin-based treatment for synchronizing ovulation for FTAI needed to control follicular dynamics. Finally, a new protocol, 'Synchrovine', was proposed that would synchronize ovulation of the first follicular wave, with two doses of PGF2 $\alpha$ given $7 \mathrm{~d}$ apart followed by FTAI $42-48 \mathrm{~h}$ later

477 (Menchaca et al. 2004). Synchrovine was based on the theory that, in a given flock with unknown phases of the estrous cycle, one PG injection will induce ovulation within four days and a second PG dose given seven days later will likely coincide with Days 3-5 after ovulation, when the largest follicle of wave 1 reaches a new ovulation and the corpora 
481 lutea are sensitive to PGF2 $\alpha$. Thus, the ovulation of wave 1 after the second PG would be

482 synchronized in the flock over a very short period, as subsequently demonstrated by Vilariño et al. (2017), and insemination can be performed without estrus detection (Menchaca and Rubianes 2004). However, when this idea was put into practice, synchronized ovulation was greater than $90 \%$ but fertility was extremely low (e.g., less than $40 \%$ ), which is not acceptable for farmers when compared to conventional protocols with progesterone and eCG. Reproductive performance using

Synchrovine was thoroughly evaluated in several studies, by different teams, in intensive experiments as well as in large-scale FTAI programs (Menchaca et al. 2004, Menchaca and Rubianes 2004, Contreras-Solis et al. 2009a, 2009b, Fierro et al. 2011, 2013; OliveraMuzante et al. 2011, 2013, Vilariño et al. 2017), but fertility was persistently low. Recently, a new hypothesis was proposed to explain this result after it was noted that that the low progesterone concentrations typical of the early luteal phase (i.e., during wave 1) are associated with poor oocyte competence (Menchaca et al., 2018, Cuadro et al. 2018). This problem is overcome when higher progesterone concentrations are imposed for a short period (i.e., during the three days from follicular wave emergence) by the administration of a CIDR-type device. Therefore, this prostaglandin-based protocol during wave 1 seems to require exogenous progesterone, an idea that should be further investigated before any recommendation of a change in protocol.

On the other hand, the longer prostaglandin-based protocols, with the second PG dose given some days later, may ensure greater progesterone concentrations (Fierro et al. 2016) and thus substitute for the addition of exogenous progesterone. However, contro, of the spread of ovulation is lost because of the control of follicular dynamics is lost, as 
506

507

508

509

510

511

512

513

514

515

516

517

518

519

520

521

522

523

524

525

526

527

528

529

530

demonstrated in cattle and sheep (Kastelic and Ginther 1991, Viñoles and Rubianes 1998, Rubianes et al. 2003). In addition, prostaglandin-based treatments require a functional corpus luteum so are not effective in anestrous females. Therefore, alternatives for progesterone-eCG based protocols should be further evaluated to achieve similar effectiveness in cycling and in anestrous females.

Alternatives to eCG, such as hCG, $\mathrm{LH}$ or $\mathrm{GnRH}$, administered near progesterone device removal have been proposed for sheep and goats. The effect of eCG on preovulatory follicles larger than $4 \mathrm{~mm}$ in the ewe is probably more similar to $\mathrm{LH}$ than $\mathrm{FSH}$, since $\mathrm{LH}$ receptors appear in the granulosa cells as the follicle increases in size (Webb and England 1982). Thus, the idea to substitute eCG with other LH active hormone is interesting but no new. The particularity of eCG is that this glycoproteic hormone incorporates particular carbohydrate side-chains with high content in sialic acid after its glycosylation. This structure confers a prolonged half-life, and thus its effect is acting for more time than other gonadotrophins (Murphy 2012). The prolonged LH support, normally provided by the endogenous LH pulse frequency during the follicular phase, is required for the normal preovulatory growth of the largest follicle (Campbell et al. 2007). In ruminant females, this support is facilitated by eCG when administrated at progesterone device removal, which improves preovulatory follicular growth and postovulatory luteal function as demonstrated in cows (Nuñez et al. 2014). This effect, however, is not provided by a single dose of GnRH or LH, since the short half-life of these hormones (Casarini et al. 2018) makes it use impractical because multiple low doses should be administrated during almost three days (i.e., from device removal to ovulation). The human chorionic gonadotrophin (hCG) has longer half-life than GnRH or LH (Casarini et al. 2018), but shorter than eCG (Nascimento et al. 2013), since this gonadotrophin has lower molecular 
531 mass and lower content of carbohydrate than eCG. The use of hCG have been used in 532 ewes after progesterone priming, sometimes associated to eCG, usually with lower 533 pregnancy rate (Cline et al. 2001). The reported results with hCG given alone after 534 intravaginal progesterone treatment are scarce in sheep, with very few animals reported, 535 and not enough information in terms of pregnancy rate is available yet.

537 Other alternatives to progesterone and eCG should be addressed, since FTAI, embryo 538 production and embryo transfer programs requires a very controlled hormonal system. Although several research teams, including us, have proposed novel ideas as alternatives to progesterone and eCG treatments, not enough validation is available to ensure equal or greater outcomes for farmers recommendation. Thus, the progesterone-based protocols have been refined and improved, and they continue being absolutely necessary to apply reproductive technologies in sheep. Genetic improvement will be impractical or with very low impact if insemination or embryo related technologies are leave aside. For the next decades, with increasing human population and food demand, good veterinary practice and global effort in programs like One Health initiative should be further developed to achieve a rational balance between food production and safety environment. Probably, novel technologies like genome editing will be available to contribute with the improvement of agriculture productivity and sustainability, as well as animal production, health and welfare. To achieve this progress, reproductive biotechnologies will be required equal or even more than before, and effective technologies should be available. 
555 The protocols based on the use of progestagens and eCG have been applied for

556 reproductive management of sheep without major change for decades. Currently, there is

557 a need to reconsider them for technical (our greatly improved knowledge of the dynamics

558 of ovarian physiology may facilitate to improve the yields) and societal reasons (animal

559 health and welfare, food safety and the environmental impact). Improvement of

560 knowledge on ovarian physiology and follicular dynamics supports the use of short-term

561 progestagen protocols (5-7 days of duration instead of 12-14 days), which also decreases

562 the appearance of vaginitis and avoids therefore the use of antibiotics. For all of these

563 reasons, short-term protocols are now being used more frequently for artificial

564 insemination of sheep under field conditions, although they are still far less popular

565 among producers than the classical long-term treatments. Clearly, we need a campaign to

566 explain and promote short-term protocols.

567

568 Short-term protocols also allow the reuse in the case of using silicone-based devices

569 (CIDR- or DICO-type); at the same time, silicone devices have advantages related to

570 animal health and welfare since allow drainage of vaginal secretions and diminishes

571 occurrence of vaginitis, and environmental impact, since the risk of liberation of

572 hormones is diminished. Therefore, as has happened in cattle, it is clear that silicone

573 intravaginal devices will replace sponges in sheep.

575 Other major concern related to the use of progestagens and eCG is the influence of

576 hormones in food safety. Such concerns, have no scientific support in the case of

577 hormones used to improve reproduction so, consequently, most of them are approved by

578 international regulatory systems and available worldwide. However, consumers operate 
579 on emotion, not data, and providing data does not change them. Having this in mind, we 580 also need to explain the safety of hormones used for breeding.

581

582 Finally, in European countries, the major concern is a strong animal rights movement 583 against the use of eCG. Barriers that reduce the availability of the hormone would hinder 584 the application of reproductive technologies with negative consequences for livestock 585 productivity and global food production. Hence, we have to look for alternative protocols without eCG, since FTAI and MOET require a very controlled hormonal system.

587

588

Although several research teams, including us, have proposed novel ideas as alternatives to progesterone and eCG treatments, not enough validation is available to ensure equal or greater outcomes for farmers recommendation. Thus, the progesterone-based protocols need to be refined and improved because they continue being absolutely necessary to apply reproductive technologies in sheep.

\section{Acknowledgments}

This research did not receive any specific funding

\section{Conflicts of interest}

The authors declare no conflicts of interest

\section{References}


604

605

606

607

608

609

610

611

612

613

614

615

616

617

618

619

620

621

622

623

624

625

626

Abecia, J.A., Forcada, F., and Gonzalez-Bulnes, A. (2012). Hormonal control of reproduction in small ruminants. Anim. Reprod. Sci. 130,173-179.

Al-Hamedawi, T.M., Khammas, D.J., and Al-Ubaidi, A.S. (2003) Effect of estrus synchronization on vaginal flora and subsequent fertility in ewes. Iraqi J. Vet. Sci. 16, 73-79.

Anadón, A., Martínez-Larrañaga, M.R., Ares, I., and Martinez, M.A. (2018). Regulatory aspects for the drugs and chemicals used in food-producing animals in the european union. veterinary toxicology basic and clinical principles (Third Edition)., Pages 103131

BCERF (Cornell University Program on Breast Cancer and Environmental Risk Factors in New York State). (2000). Fact Sheet \# 37: Consumer Concerns about Hormones in Food. http://www.cfe.cornell.edu/bcerf/

Berlinguer, F., Gonzalez-Bulnes, A., Succu, S., Leoni, G., Mossa, F., Bebbere, D., Ariznavarreta, C., and Tresguerres, J.A.F. (2007) Effects of progestagens on follicular growth and oocyte developmental competence in FSH-treated ewes. Dom. Anim. Endocrinol. 32, 303-314.

Boland, M.P., Gordon, I., and Kelleher, D.L. (1978). The effect of treatment by prostaglandin analogue (ICI-80, 996) or progestagen (SC-9880) on ovulation and fertilization in cyclic ewes. J. Agric. Sci. 91, 727-730.

Bragança, J.F.M., Maciel, J.M., Girardini, L.K., Machado, S.A., da Rocha, J.F.X., Tonin, A.A., and da Rocha, R.X. (2017). Influence of a device intravaginal to synchronization/induction of estrus and its reuse in sheep vaginal flora. Comp. Clin. Pathol. 26, 1369-1373. 
627 Campbell B.K., Kendall N.R., and Baird, D.T. (2007). The effect of the presence and

628

629

630

631

632

633

634

635

636

637

638

639

640

641

642

643

644

645

646

647

648

649

650 pattern of luteinizing hormone stimulation on ovulatory follicle development in sheep. Biol. Reprod. 76, 719-727.

Carvalho, J.B.P., Carvalho, N.A.T., Reis, E.L., Nichi, M., Souza, A.H., and Baruselli, P.S. (2008). Effect of early luteolysis in progesterone-based timed AI protocols in Bos indicus, Bos indicus $\times$ Bos taurus, and Bos taurus heifers. Theriogenology 69 , $167-175$.

Casarini, L., Santi, D., Brigante, G., and Simoni, M. (2018). Two hormones for one receptor: Evolution, biochemistry, actions, and pathophysiology of LH and hCG. Endocrine Rev. 39, 549-592.

Cline, M. A., Ralston, J. N., Seals, R. C., and Lewis G-S. (2001). Intervals from norgestomet withdrawal and injection of equine chorionic gonadotropin or P.G. 600 to estrus and ovulation in ewes. J. Anim. Sci. 79, 589-594.

Contreras-Solis, I., Vasquez, B., Diaz, T., Letelier, C., Lopez-Sebastian, A., and Gonzalez-Bulnes, A. (2009). Ovarian and endocrine responses in tropical sheep treated with reduced doses of cloprostenol. Anim. Reprod. Sci. 114, 384-392.

Contreras-Solis, I., Vasquez, B., Diaz, T., Letelier, C., Lopez-Sebastian, A., and Gonzalez-Bulnes, A. (2009). Efficiency of estrous synchronization in tropical sheep by combining short-interval cloprostenol-based protocols and "male effect". Theriogenology 71, 1018-1025.

Cox, J.F., Allende, R., Lara, E., Leiva, A., Díaz, T., Dorado, J., and Saravia, F. (2012). Follicular dynamics, interval to ovulation and fertility after AI in short-term progesterone and PGF2 $\alpha$ oestrous synchronization protocol in sheep. Reprod. Dom. Anim. 47, 946-951. 
651 Cuadro, F., dos Santos-Neto, P.C., Pinczak, A., Barrera, N, Crispo, M., and Menchaca, 652 A. (2018). Serum progesterone concentrations during FSH superstimulation of the 653 first follicular wave affect embryo production in sheep. Anim. Reprod. Sci. 196, 205654210.

655 de Graaff, W., Grimard, B. (2018). Progesterone-releasing devices for cattle estrus 656 induction and synchronization: Device optimization to anticipate shorter treatment 657 durations and new device developments. Theriogenology 112, 34-43

658

659

660

661

662

663

664

665

666

667

668

669

670

671

672

673

674 dos Santos-Neto, P.C., García-Pintos, C., Pinczak, A., and Menchaca, A. (2015). Fertility obtained with different progestogen intravaginal devices using short-term protocol for fixed-time artificial insemination (FTAI) in sheep. Livestock Sci. 182, 125-128.

Dutt, R.H. (1952). Induction of oestrus and ovulation in anestrual ewes by the use of progesterone and pregnant mares serum. J. Anim. Sci. 11, 792.

Dutt, R.H., and Casida, L.E. (1948). Alteration of the estrual cycle in sheep by use of progesterone and its effect upon subsequent ovulation and fertility. Endocrinology. 43, 208-217.

Evans, A.C.O. (2003). Ovarian follicle growth and consequences for fertility in sheep. Anim. Reprod. Sci. 78, 289-306.

Evans, G., Maxwell, W.M.C., and Salamon, S. (1987). Salamon's artificial insemination of sheep and goats. Butterworth Press \& Co, Sydney, Australia.

Fierro, S., Gil, J., Vinoles, C., and Olivera-Muzante, J. (2013). The use of prostaglandins in controlling estrous cycle of the ewe: a review. Theriogenology 79, 399-408.

Fierro, S., Olivera-Muzante, J., Gil, J., and Viñoles, C. (2011). Effects of prostaglandin administration on ovarian follicular dynamics, conception, prolificacy, and fecundity in sheep. Theriogenology, 76, 630-639. 
675 Fierro, S., Viñoles, C., and Olivera-Muzante, J. (2016). Concentrations of steroid 676 hormones, estrous, ovarian and reproductive responses in sheep estrous synchronized with different prostaglandin-based protocols. Anim. Reprod. Sci. 167, 74-82.

678

Fingleton, J. (2004). Legislation for veterinary drugs control. FAO Legal Papers Online \#38 http://www.fao.org/3/a-bb071e.pdf access 10112018.

Fournier, A., Mesrine, S., Dossus, L., Boutron-Ruault, M.C., Clavel-Chapelon, F., and Chabbert-Buffet, N. (2014). Risk of breast cancer after stopping menopausal hormone therapy in the E3N cohort. Breast Cancer Res. Treat. 535-543.

Gatti, M., Zunino, P., and Ungerfeld, R. (2011). Changes in the aerobic vaginal bacterial mucous load after treatment with intravaginal sponges in anoestrous ewes: effect of medroxiprogesterone acetate and antibiotic treatment use. Reprod. Dom. Anim. 46, 205-208.

Gonzalez-Bulnes, A., Garcia, P., Veiga-Lopez, A., Garcia-Garcia, R.M., Ariznavarreta, C., and Sanchez, A. (2005). Effects of progestagens and prostaglandin analogues on ovarian function and embryo viability in sheep. Theriogenology 63, 2523-2534.

Goodman RL, and Karsh FJ. (1980). Pulsatile secretion of luteinizing hormone: differential suppression by ovarian steroids. Endocrinology 107, 1286-90.

Gordon I. (1975). Hormonal control of reproduction in sheep. Proc. Br. Soc. Anim. Prod. 4, 79-93.

Gordon, I. (1983). Controlled breeding in farm animals. (First ed.), Pergamon Press, Oxford, UK

Hackett, A.J., Robertson, H.A., and Wolynetz, M.S. (1981). Effects of prostaglandin F2 alpha and pregnant mares' serum gonadotropin (PMSG) on the reproductive performance of fluorogestone acetate PMSG-treated ewes. J. Anim. Sci. 53, 154-159. 
Hamra, A.H., J.W. McNally, J.M. Marcek, K.M. Carlson and J.E. Wheaton. (1989). Comparison of progesterone sponges, cronolone sponges, and controlled internal drug release dispensers on fertility in anestrous ewes. Anim. Reprod. Sci. 18, 219226.

Hamra, A.H., Massri, Y.G., Marcek, J.M., and Wheaton, J.E. (1986). Plasma Progesterone levels in ewes treated with progesterone controlled internal drug release dispensers, implants and sponges. Anim. Reprod. Sci. 11, 187-194.

Hawk, H.W., and Conley, H.H. (1971). Sperm transport in ewes administered synthetic progestagen. J. Anim. Sci. 33, 255-256.

Johnson, S.K., Dailey, R.A., Inskeep, E.K., and Lewis, P.E. (1996). Effect of peripheral concentrations of progesterone on follicular growth and fertility in ewes. Dom. Anim. Endocrinol. 13, 69-79.

Kastelic, J.P., and Ginther, O.J. (1991). Factors affecting the origin of the ovulatory follicle in heifers with induced luteolysis. Anim. Reprod. Sci. 26, 13-24.

Killian, D.B., Kiesling, D.O., and Warren, J.R. (1985). Lifespan of corpora lutea induced in estrous-synchronized cycling and anoestrous ewes. J. Anim. Sci. 61, 210-218.

Knight, T.W., and Hall, D.R.H. (1988). Effect of immunisation withpolyandroalbumin (Fecundin); pasture allowance, post-mating shearing and method of synchronisation on reproductive performance of Romney and Marshall Romney ewes. New Zealand J. Agric. Res. 31, 243-247

Knights, M., Maze, T.D., Bridges, P.J., Lewis, P.E., and Inskeep, E.K. (2001). Short-term treatment with a controlled internal drug releasing (CIDR) device and FSH to induce fertile estrus and increase prolificacy in anestrous ewes. Theriogenology 55, 11811191. 
Letelier, C.A., Contreras-Solis, I., García-Fernández, R.A., Ariznavarreta, C., Tresguerres, J.A., Flores, J.M., and Gonzalez-Bulnes, A. (2009). Ovarian follicular dynamics and plasma steroid concentrations are not significantly different in ewes given intravaginal sponges containing either 20 or $40 \mathrm{mg}$ of fluorogestone acetate. Theriogenology 71, 676-682.

Lewis, G.S. (2003) Steroidal regulation of uterine resistance to bacterial infection in livestock. Reprod. Biol. Endocrinol. 1, 117-124

Leyva, V., Buckrell, B.C., and Walton, J.S. (1998). Regulation of follicular activity and ovulation in ewes by exogenous progestagen. Theriogenology 50, 395-416.

Mapletoft, R.J., Bó, G.A., Baruselli, P.S., Menchaca, A., and Sartori, R. (2018). Evolution of knowledge on ovarian physiology and its contribution to the widespread application of reproductive biotechnologies in South American cattle. Anim. Reprod. 15, 1003-1014.

Martin, G.B. (1995). Reproductive research on farm animals for Australia - some longdistance goals. Reprod. Fertil. Develop. 7, 967-982.

Martin, G.B., Milton, J.T.B., Davidson, R.H., Banchero Hunzicker, G.E., Lindsay, D.R., and Blache, D. (2004). Natural methods of increasing reproductive efficiency in sheep and goats. Anim. Reprod. Sci. 82-83, 231-246.

Martinez-Ros, P., Astiz, S., Garcia-Rosello, E., Rios-Abellan, A., and Gonzalez-Bulnes, A. 2018a. Onset of estrus and preovulatory LH surge and ovulatory efficiency in sheep after short-term treatments with progestagen-sponges and progesterone-CIDRs. Reprod. Dom. Anim. 00, 1-4. DOI: 10.1111/rda.13317

Martinez-Ros, P., Astiz, S., Garcia-Rosello, E., Rios-Abellan, A., and Gonzalez-Bulnes, A. 2018b. Effects of short-term intravaginal progestagens on the onset and features 
of estrus, preovulatory LH surge and ovulation in sheep. Anim. Reprod. Sci. 197, $317-323$

Martins, G., Figueira, B., Penna, B., Brandão, F., Varges, R., Vasconcelos, C., and Lilenbaum, W. (2009). Prevalence and antimicrobial susceptibility of vaginal bacteria from ewes treated with progestin-impregnated intravaginal sponges. Small Rumin. Res. 81, 182-184

McNeilly, A.S., Hunter, M., Land, R.B., and Fraser, H.M. (1981). Inadequate corpus luteum function after the induction of ovulation in anoestrous ewes by LH-RH or an LH-RH agonist. J. Reprod. Fertil. 63, 137-144.

Menchaca, A., \& Rubianes, E. (2004). New treatments associated with timed artificial insemination in small ruminants. Reprod. Fertil. Dev. 16, 403-414.

Menchaca, A., Cuadro, F., dos Santos-Neto, P.C., Bosolasco, D., Barrera, N., de Brun, V., and Crispo, M. (2018). Oocyte developmental competence is improved by relatively greater circulating progesterone concentrations during preovulatory follicular growth. Anim. Reprod. Sci. 195, 321-328.

Menchaca, A., dos Santos-Neto, P.C., Cuadro, F., Souza-Neves, M., Crispo, M. (2018). From reproductive technologies to genome editing in small ruminants: an embryo's journey. Anim. Reprod. 15, 984-995.

Menchaca, A., Miller, V., Gil, J., Pinczak, A., Laca, M., Rubianes, E. (2004). Prostaglandin F2alpha treatment associated with timed artificial insemination in ewes. Reprod. Dom. Anim. 39, 352-355.

Murphy, B.D. (2012). Equine chorionic gonadotropin: an enigmatic but essential tool. Anim. Reprod. 9, 223-230. 
NAMS (North American Menopause Society). (2017). Scientific Background Report for the 2017 Hormone Therapy Position Statement of The North American Menopause Society. www.menopause.org

Nascimento, A.B., Bender, R.W., Souza, A.H., Ayres, H., Araujo, R.R., Guenther, J.N., Sartori, R., and Wiltbank, M.C. (2013). Effect of treatment with human chorionic gonadotropin on day 5 after timed artificial insemination on fertility of lactating dairy cows. J. Dairy Sci. 96, 2873-2882.

Nöel, B., Bister, J.L., Pierquin, B., and Paquay, R. (1994). Effects of FGA and PMSG on follicular growth and LH secretion in Suffolk ewes. Theriogenology 41, 719-727.

Núñez-Olivera, R., de Castro, T., García-Pintos, C., Bo, G., Piaggio, J., and Menchaca, A. (2014). Ovulatory response and luteal function after eCG administration at the end of a progesterone and estradiol' based treatment in postpartum anestrous beef cattle. Anim. Reprod. Sci. 146, 111-116.

Olivera-Muzante, J., Fierro, S., Lopez, V., and Gil, J. (2011). Comparison of prostaglandin- and progesterone-based protocols for timed artificial insemination in sheep. Theriogenology 75, 1232-1238.

Olivera-Muzante, J., Gil, J. Vinoles, C., and Fierro, S. (2013). Reproductive outcome with GnRH inclusion at 24 or $36 \mathrm{~h}$ following a prostaglandin F2alpha-based protocol for timed AI in ewes. Anim. Reprod. Sci. 138, 175-179.

Passantino A (2012). Steroid Hormones in Food Producing Animals: A Bird's-Eye View of Veterinary Medicine, Dr. Carlos C. Perez-Marin (Ed.), ISBN: 978-953-51-00317, InTech, Available from: http://www.intechopen.com/books/a-bird-s-eye-view-ofveterinary-medicine/title-steroid-hormones-in-foodproducing-animals-regulatorysituation-in-europe. 
Pinna, A.E., Brandão, F.Z., Cavalcanti, A.S., Borges, A.M., Souza, J.M.G., and Fonseca, J.F. (2012). Reproductive parameters of Santa Inês ewes submitted to short-term treatment with re-used progesterone devices. Arq. Brasil. Med. Vet. Zootec. 64, 333340.

Rathbone, M.J., and Burke, C.R. (2012). Controlled release intravaginal veterinary drug delivery. In: Rathbone MJ, McDowell A, editors. Long acting animal health drug products: fundamentals and applications. London: Springer;. 247-270.

Regal, P., Cepeda, A., and Fente, C.A. (2012). Natural Hormones in Food-Producing Animals: Legal Measurements and Analytical Implications, Food Production Approaches, Challenges and Tasks, Prof. Anna Aladjadjiyan (Ed.), ISBN: 978-953307-887-8, InTech, Available from: http://www.intechopen.com/books/foodproduction-approaches-challenges-and-tasks/natural-hormones-infood-producinganimals-legal-measurements-and-analytical-implications.

Robinson, T.J. (1952). Role of progesterone in the mating behaviour of the ewe. Nature 170, 373-374.

Robinson, T.J. (1964). Synchronization of oestrus in sheep by intra-vaginal and subcutaneous application of progestin impregnated sponges. Proc. Aust. Soc. Anim. Prod. 8, 47-49.

Robinson, T.J. (1965). Use of progestagen-impregnated sponges inserted intravaginally or subcutaneously for the control of the oestrous cycle in the sheep. Nature 206, 3941.

Robinson, T.J., and Lamond D.R. (1966). Control of reproduction in sheep and cattle. Proc. Aust. Soc. Anim. Prod. 6, 10-18.

Rubianes, E., Menchaca, A., and Carbajal, B. (2003). Response of the 1-5 day-aged ovine corpus luteum to prostaglandin F2alpha. Anim. Reprod. Sci. 78, 47-55. 
819 Rutter, J.M. (1993). Licensing of Veterinary Vaccines and Biologicals. FAO Animal 820 Production and Health Paper No. 116, FAO, Rome.

821

822

Sargison, N.D., Howie, F., Mearns, R., Penny, C.D., and Foster, G. (2007) Shiga toxinproducing Escherichia coli as a perennial cause of abortion in a closed flock of Suffolk ewes. Vet. Record 160, 875-876.

Scaramuzzi, R.J., Downing, J.A., Campbell, B.K., and Cognie, Y. (1988). Control of fertility and fecundity of sheep by means of hormonal manipulation. Austr. J. Biol. Sci. 41, 37-45.

Scudamore, C.L. (1988) Intravaginal sponge insertion technique. Vet. Record 123, 554

Shelton, J. N. (1965). Identification of progestogens of high activity for the control of the oestrous cycle in the sheep. Nature 206, 156-158.

Suarez, G., Zunino, P., Carol, H., and Ungerfeld, R. (2006). Changes in the aerobic vaginal bacterial mucous load and assessment of the susceptibility to antibiotics after treatment with intravaginal sponges in anestrous ewes Small Rumin. Res. 63, 39-43.

Swartz, J.D., Lachman, M., Westveer, K., O'Neill, T., Geary, T., Kott, R.W., Berardinelli, J.G., Hatfield, P.G., Thomson, J.M., Roberts, A., and Yeoman, C.J. (2014). Characterization of the vaginal microbiota of ewes and cows reveals a unique microbiota with low levels of lactobacilli and near-neutral pH. Frontiers Vet. Sci. 1, 19.

Ungerfeld, R., and Rubianes, E. (1999). Effectiveness of short-term progestagen primings for the induction of fertile estrus with eCG in ewes during late seasonal anestrus. Anim. Sci. 68, 349-353.

Vasconcelos, C., Brandão, F.Z., Martins, G., Penna, B., Souza, J.M.G., and Lilenbaum, W. (2016) Qualitative and quantitative analysis of bacteria from vaginitis associated 
with intravaginal implants in ewes following estrus synchronization. Ciência Rural, Santa Maria 46, 632-636.

Vilariño, M., Cuadro, F., dos Santos-Neto, P.C., García-Pintos, C., Menchaca, A. (2017). Time of ovulation and pregnancy outcomes obtained with the prostaglandin-based protocol Synchrovine for FTAI in sheep. Theriogenology 90, 163-168.

Vilariño, M., Rubianes, E., and Menchaca, A. (2013). Ovarian responses and pregnancy rate with previously used intravaginal progesterone releasing devices for fixed-time artificial insemination in sheep. Theriogenology 79, 206-210.

Vilariño, M., Rubianes, E., van Lier, E., and Menchaca, A. (2010). Serum progesterone concentrations, follicular development and time of ovulation using a new progesterone releasing device (DICO). Small Rumin. Res. 91, 219-224.

Viñoles, C., and Rubianes, E. (1998). Origin of the preovulatory follicle after induced luteolysis during the early luteal phase in ewes. Can. J. Anim. Sci. 78, 429-431.

Viñoles, C., Forsberg, M., Banchero, G., and Rubianes, E. (2001). Effect of long-term and short-term progestagen treatment on follicular development and pregnancy rate in cyclic ewes. Theriogenology 55, 993-1004.

Viñoles, C., Meikle, A., Forsberg, M., and Rubianes, E. (1999). The effect of subluteal 860 levels of exogenous progesterone on follicular dynamics and endocrine patterns during the early luteal phase of the ewe. Theriogenology 51, 1351-1361.

Webb, R., and England, B.G. (1982). Identification of the ovulatory follicle in the ewe: Associated changes in follicular size, thecal and granulosa cell luteinizing hormone receptors, antral fluid steroids, and circulating hormones during the preovulatory period. Endocrinology 110, 873-881. 
866 Wheaton, J.E., Carlson, K.M., Windels, H.F., and Johnston, L.J. (1993). CIDR - a new 867 progesterone-releasing intravaginal device for induction of estrus and cycle control 868 in sheep and goats. Anim. Reprod. Sci. 33, 127-141.

869 Wiltbank, M.C., and Niswender, G.D. (1992). Functional aspects of differentiation and 870 degeneration of the steroidogenic cells of the corpus luteum in domestic ruminants. 871 Anim. Reprod. Sci. 28, 103-110.

872 


\section{$873 \quad$ Figure captions}

874

875 Figure 1. Intravaginal devices used for induction and synchronization of estrus and ovulation in sheep; intravaginal sponges (A and B), DICO (C) and CIDR (D).

877

878 Figure 2. Seventy years of progestogens treatments in the ewe. Since the first report in 8791948 , progesterone and its analogues have been used to control the ovine estrous cycle. 880 In the 1950s, daily progesterone injections treatment was associated to equine chorionic 881 gonadotrophin (eCG) administration at the end of the protocol, which allowed the 882 synchronization of ovulation during breeding and non-breeding season. In the 1960s, the 883 main progress was the development of intravaginal sponges impregnated with the novel progesterone analogues flugestone (FGA) and medroxyprogesterone (MPA) acetate. In the 1980s and 1990s, the evolution in controlled drug releasing systems enabled the design of siliconed CIDR-type devices. Finally, in the 2000s the protocols for Fixed-time

887 Artificial Insemination (FTAI) were reduced to 6-7 days, and nowadays they have been 888 validated during breeding and non-breeding season, with cervical, transcervical and intrauterine insemination, using both fresh and frozen semen. 


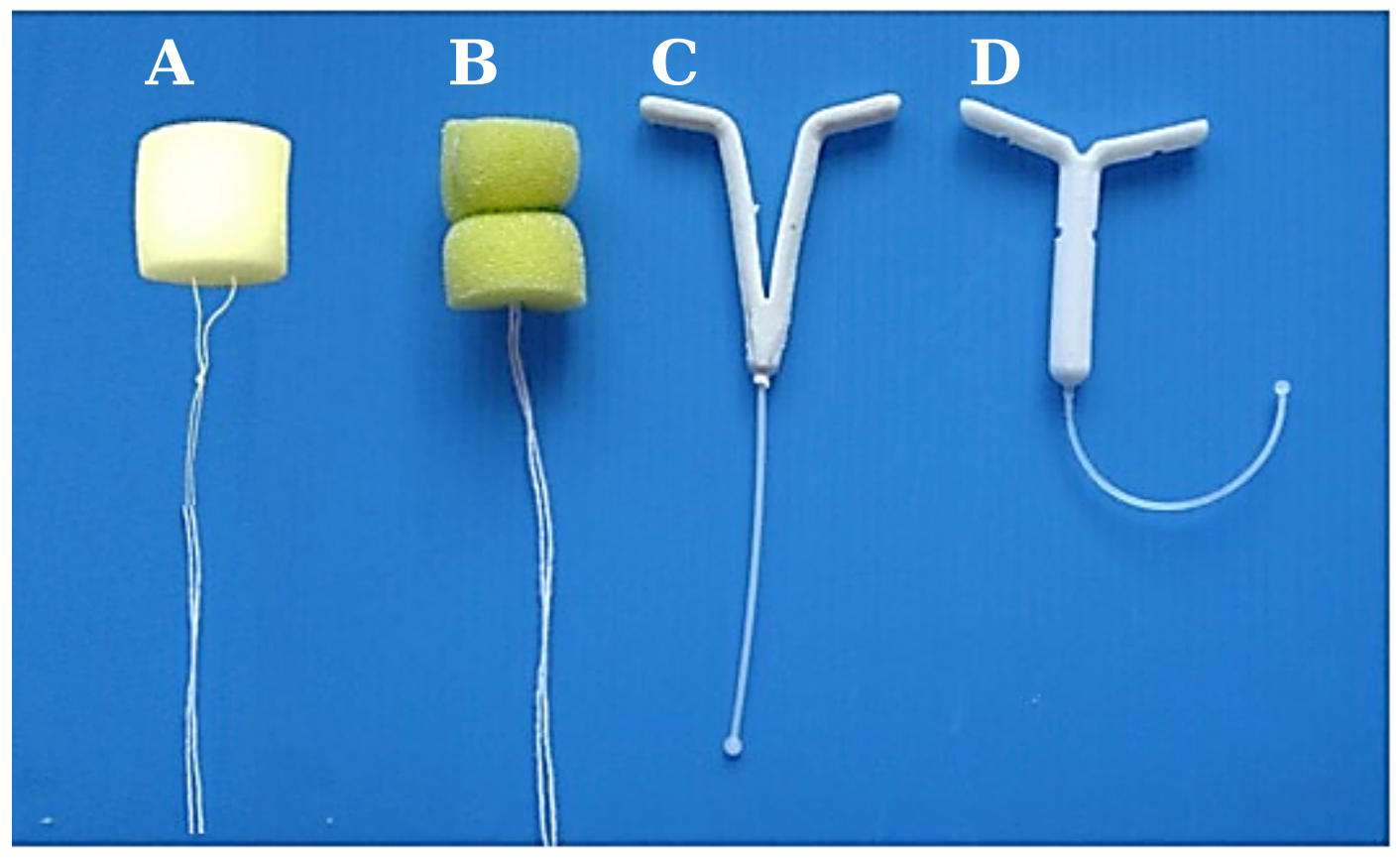



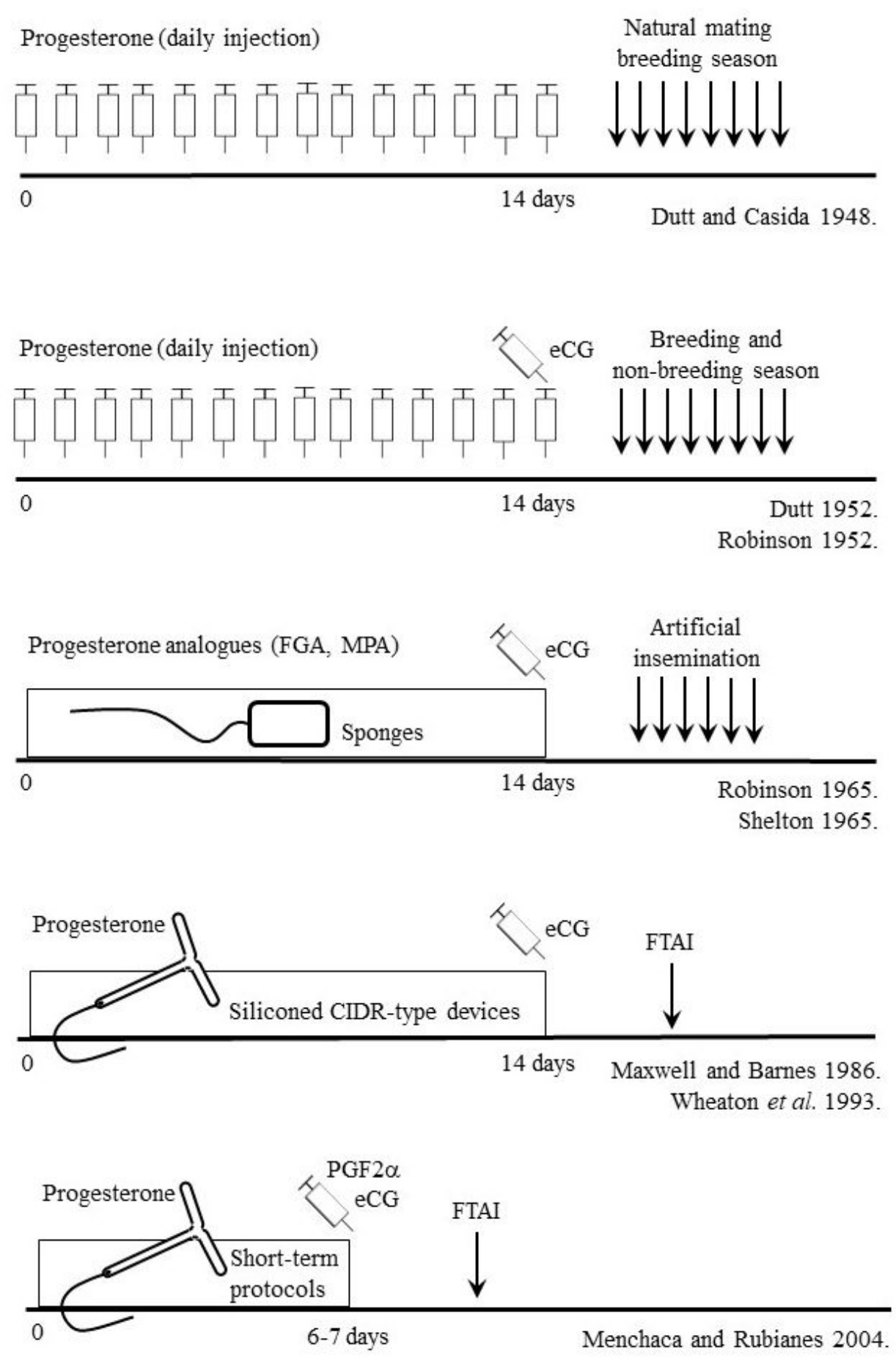

Figure 2. Seventy years of progestogens treatments in the ewe. Since the first report in 1948, progesterone and its analogues have been used to control the ovine estrous cycle. In the 1950s, daily progesterone injections treatment was associated to equine chorionic gonadotrophin (eCG) administration at the end of the protocol, which allowed the synchronization of ovulation during breeding and non-breeding season. In the 1960s, the main progress was the development of intravaginal sponges impregnated with the novel progesterone analogues flugestone (FGA) and medroxyprogesterone (MPA) acetate. In the 1980s and 1990s, the evolution in controlled drug releasing systems enabled the design of siliconed CIDR-type devices. Finally, in the 2000s the protocols for Fixed-time Artificial Insemination (FTAI) were reduced to 6-7 days, and nowadays they have been validated during breeding and non-breeding season, with cervical, transcervical and intrauterine insemination, using both fresh and frozen semen. 